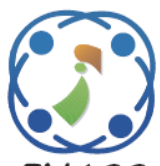

\title{
Optimization of E-Shaped Microstrip Patch Antenna Using Particle Swarm Optimization (PSO) for Wideband Application
}

\author{
Yulindon Yulindon ${ }^{1,2 *} \quad$ Noor Azah Samsudin $^{1} \quad$ Riswan Efendi $^{1,3}$ \\ ${ }^{1}$ Universiti Tun Hussein Onn Malaysia, Malaysia \\ ${ }^{2}$ Politeknik Negeri Padang, Indonesia \\ ${ }^{3}$ UIN Sultan Syarif Kasim Riau, Indonesia \\ * Corresponding author's email: yulindon@pnp.ac.id
}

\begin{abstract}
The antenna simulation is generally done manually where certain antenna parameters are changed by trial and error method until the desired performance is obtained. In this study, the E-shaped microstrip antenna was designed to work in wideband frequency using the Particle Swarm Optimization (PSO) algorithm. The E-shaped patch antenna with ground follows the subtraction size. The type of substrate used in this study is FR4 Epoxy with a relative dielectric constant value $(r)=4.6$ and thickness $(h)=1.6 \mathrm{~mm}$. Feeding technique used in the connector is a probe feed technique to get matching impedance that matches the impedance of the connector which is $50 \mathrm{ohms}$. The working frequency of the E-shaped microstrip antenna after the use of the PSO algorithm generated bandwidth of $295 \mathrm{MHz}$ with a working frequency of 340-635 MHz. From several stages of optimization performed, an ideal gain is obtained in accordance with the characteristics of the E-shaped antenna, where the resulting gain is $3.246 \mathrm{dBi}$. The characteristic obtained is omnidirectional, where the donut-shaped radiation pattern with the direction of the wave is in all directions.
\end{abstract}

Keywords: E-shaped microstrip patch antenna, Particle swarm optimization (PSO), Wideband.

\section{Introduction}

At first, the microstrip antenna design was done conventionally. In other words, design methods are still carried out by calculating the relevant parameters manually. These parameters are of course still related to the electromagnetic characteristics possessed by an antenna. Based on the manual calculation results, it is then applied. If an antenna is not produced with the performance that meets the design specifications, improvements and optimizations are made in the design. This conventional antenna design step is inefficient and not economical. A new alternative besides the method is to use one of the optimization methods, the Particle Swarm Optimization (PSO) algorithm. This method is useful when dealing with formulas whose purpose is to find optimal results. The problem that arises is determining what parameter variables must be processed and how many iterations of calculations must be done. In addition, regarding how to connect the Particle Swarm
Optimization algorithm method to the formula of the microstrip antenna, a software is needed to solve this problem [1-3].

Some existing research on antenna optimization has been already done and found on some publications. The exponential Log-Periodic Antenna design have been optimized using Particle Swarm Optimization with velocity mutation for the frequency 790-6000MHz application [4]. Meanwhile the optimization of Z-Shape Microstrip Antenna with I-slot using Discrete Particle Swarm Optimization (DPSO) algorithm are proposed for Wi-Max/S-band and C-band satellite application [5]. A modified ground structure for Radio Frequency Identification (RFID) has been utilized for a dual-band monopole microstrip antenna [6]. The Teaching-LearningOptimization (TLBO) algorithm has been utilized to design a dual-band E-shaped patch antenna for $5 \mathrm{G}$ network [7]. Rectangular, triangular and E-shaped microstrip patch antenna arrays have been tested and compared for wireless sensor networks due to usually 
wireless sensor nodes use omnidirectional antennas to broadcast data [8]. E-shaped and U-slot patches antenna with linear polarization is utilized in WLAN $(2.40-2.4835 \mathrm{GHz})$ and WiMAX $(3.40-3.61 \mathrm{GHz})$ bands [9]. A chaotic particle swarm optimization (CPSO) algorithm has been utilized to optimize an Eshaped patch microstrip antenna [10].

However, all of the optimized microstrip antennas above are not the E-shape microstrip antennas. In this paper, the optimization of antenna design is intended for the wideband applications that have frequencies below $1 \mathrm{GHz}$. Thus, an optimization of the E-shaped microstrip patch antenna needs to be done in order to work on the UHF band applications. Thus, an E-shaped microstrip antenna is designed to work at wideband frequencies, and the design uses antenna simulation software to optimize. Microstrip antennas with E-shaped patch structures have the advantage on having the frequency response with a $30 \%$ wider bandwidth than rectangular patch antennas [11]. This E-shaped antenna also has a wider bandwidth than an antenna with $\mathrm{U}$ and $\mathrm{H}$ shaped structures for WLAN applications [12]. In the form of array arrays in addition to having a wide bandwidth, the E-shaped antenna structure also produces high gain [13].

The rest of this paper is organized as follows. Section 2 explains the antenna design, section 3 explains particle swarm optimization (PSO), section 4 explains design and results. Last, the conclusion is presented in section 5 .

\section{Antenna design}

The E-shaped antenna is a rectangular microstrip antenna that modifies the radiator patch to increase bandwidth. When compared to other patch modification antennas, E-shaped antennas have the widest bandwidth up to $30 \%$ bandwidth and are more easily realized [11].

Therefore, in this study, a microstrip antenna will be designed with the E-shaped method that can work in several wideband frequencies with return loss values below $-10 \mathrm{~dB}$ and VSWR at $1<\mathrm{X}<2$.

\subsection{Determination of antenna specifications}

The parameters observed in this simulation are return loss, VSWR and matching impedance generated in the design to determine the received power can be transmitted perfectly. To design an antenna in accordance with the desired characteristics required the right specifications, then the specifications of the E-Shaped microstrip antenna.
Table 1. The antenna characteristics to be achieved

\begin{tabular}{|l|l|}
\hline Frequency & $\begin{array}{l}\text { Between the range of 400- } \\
900 \mathrm{MHz}\end{array}$ \\
\hline Return loss & $<-10 \mathrm{~dB}$ \\
\hline VSWR & $1<\mathrm{VSWR}<2$ \\
\hline Gain & $3.2 \mathrm{~dB}$ \\
\hline Radiation pattern & Omnidirectional \\
\hline
\end{tabular}

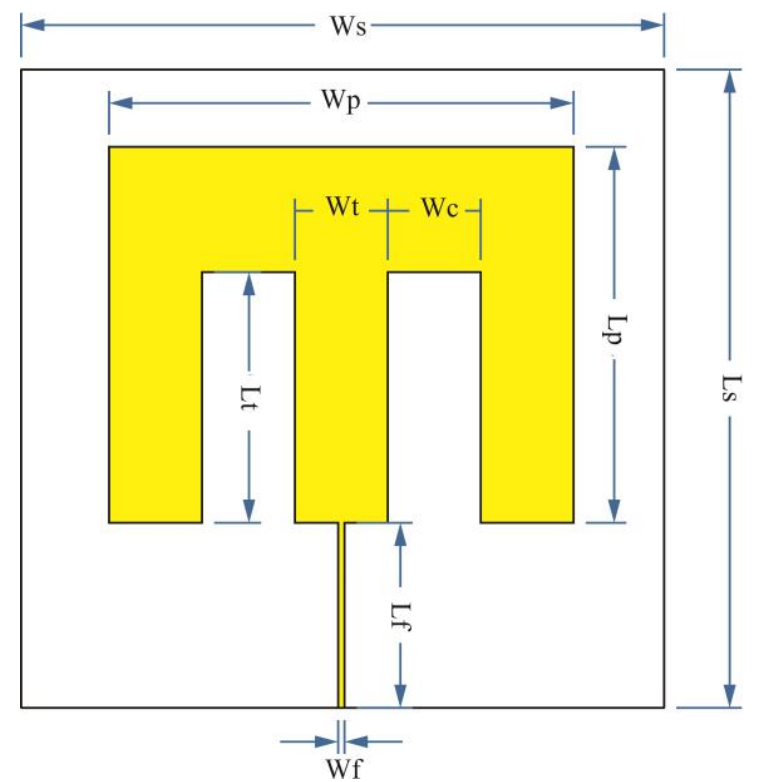

Figure. 1 Front antenna parameters

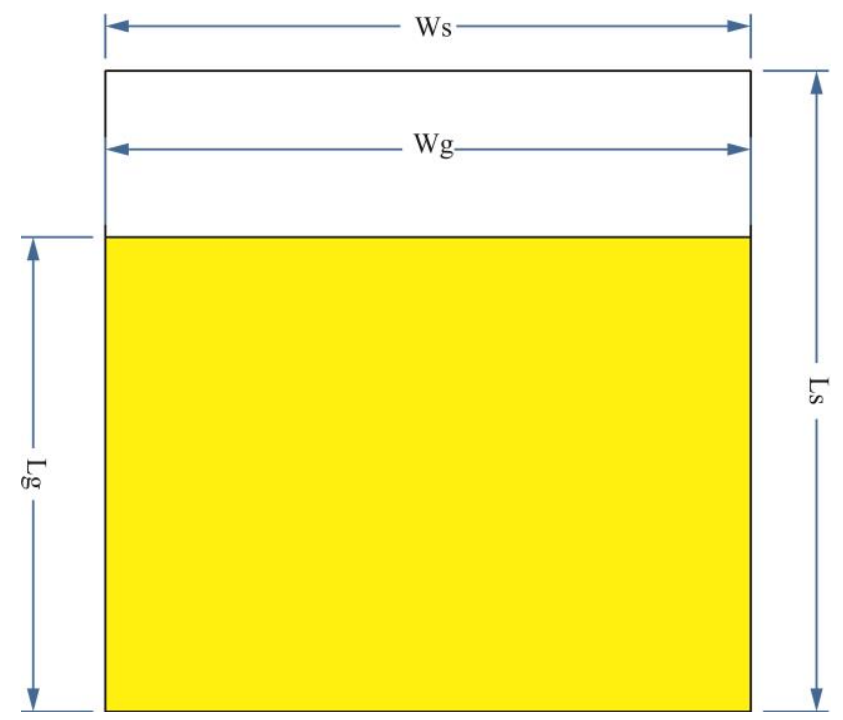

Figure. 2 Rear antenna parameters

\subsection{Antenna dimensions calculation}

This calculation is needed to find out how much the antenna dimensions will be simulated then after that antenna is realized. The antenna calculation includes two parts, namely the dimensions of the patch and also the dimensions of the groundplane. 
The design of the proposed E-shaped microstrip patch antenna is shown in Fig. 1. $W p$ and $L p$ indicates the patch width and the patch length respectively. Thus, the size of the metallic radiating patch of the proposed antenna is $L p \times W p$. Besides, $W s$ and $L s$ indicates the width, and substract length respectively. Thus, the size of the length of the proposed antenna is $W s \times L s$. Moreover, $W f, L f, L t, W t$, and $W c$ indicates the feed width, feed length, termination length, termination width, and gap width respectively.

Patches function as components that radiate electromagnetic waves into free space. The E-shaped microstrip patch antenna parameter is calculated as follows:

1. Calculation for feed width $(W f)$

$$
W f=\frac{2 x h}{\pi}\left\{\begin{array}{l}
B-1-\operatorname{Ln}(2 B-1)+\frac{E r-1}{2 x E r} \\
x\left(\operatorname{Ln}(B-1)+0.39-\frac{0.61}{E r}\right)
\end{array}\right\}
$$

Using this formula, the width of feed $=3 \mathrm{~mm}$ is obtained.

2. Calculation for feed length $(L f)$

Using this formula, we get the value of feed length $=50 \mathrm{~mm}$.

$$
L f=\frac{\left(\frac{C}{C x \sqrt{E r}}\right)}{4}
$$

3. Calculate patch length $(W p)$

$$
W p=\frac{\left(\frac{c}{2 \cdot f \cdot(\sqrt{E r+1})}\right)}{2}
$$

Using this formula, the width of feed $=181.1 \mathrm{~mm}$ is obtained.

4. Calculate patch length $(L p)$

$$
\begin{aligned}
& \left.E f f=\left(\frac{E r+1}{2}\right)+\left(\frac{E r-1}{2}\right)(1+\sqrt{(12 \cdot h}) / w\right) \\
& \Delta l=(0,412 . h)\left(\frac{(E f+0.3) \cdot\left(\left(\frac{w}{h}\right)+0.264\right)}{(E f-0,258) \cdot\left(\left(\frac{w}{h}\right)+0.8\right)}\right) \\
& \text { Leff }=\frac{C}{2 . f . \sqrt{E f f}} \\
& L p=\text { Leff }-2 \Delta l
\end{aligned}
$$

Using this formula, the patch length value of 99.4 $\mathrm{mm}$ is obtained.

5. Calculate the length of the subtract and the length of the ground

$$
L s=12 h+2 L p
$$

Table 2. The antenna parameter

\begin{tabular}{|l|c|}
\hline \multicolumn{1}{|c|}{ Parameter } & Dimension $(\mathrm{mm})$ \\
\hline Length of patch $(L p)$ & 99.4 \\
\hline Width of patch $(W p)$ & 181.1 \\
\hline Length of feed $(L f)$ & 50 \\
\hline Width of feed $(W f)$ & 3 \\
\hline Length of termination $(L t)$ & 120 \\
\hline Width of termination $(W t)$ & 42 \\
\hline Width of gap $(W c)$ & 42 \\
\hline Length of substract $(L s)$ & 218 \\
\hline Width of substract $(W S)$ & 381.4 \\
\hline Length of ground $(L g)$ & 218 \\
\hline Width of ground $(W g)$ & 381.4 \\
\hline
\end{tabular}

Using this formula, the substract length $=218 \mathrm{~mm}$ is obtained.

6. Calculate the width of the subtract and the width of the ground

$$
W s=12 h+2 L p
$$

Using this formula, the substract length $=381.4$ $\mathrm{mm}$ is obtained.

The proposed E-shaped microstrip patch antenna is simulated in CST simulator using simulation parameters listed in Table 2.

\section{Particle swarm optimization}

The Particle Swarm Optimization (PSO) algorithm is an optimization algorithm whose work is inspired by the social behaviour of bird flocking or fish schooling. PSO algorithm is an optimization algorithm that works based on population-based search, where each individual or commonly called particles will change their position with respect to time. In this PSO algorithm, the particles will fly along the multidimensional search space and will adjust their position based on their experience and based on the experience of the particles next to them. From the above explanation it can be concluded that the PSO algorithm combines 2 methods, namely the local search method with the global search method.

The initialization of the PSO optimization algorithm is started by randomly determining the initial position of the particles and then the particles will find the optimal value by updating their position. Each iteration of each particle will update its position based on the two best values, namely the best solution obtained by each particle (Pbest) and the best solution based on population (Gbest). After getting the two best values, the position and speed of the particles will be updated using the following equation [14]: 


$$
\begin{aligned}
v_{i}^{k}= & w v_{i}^{k}+c_{1} r_{1}\left(\text { Pbest }_{i}^{k}-x_{i}^{k}\right) \\
& +c_{2} r_{2}\left(\text { Gbest }^{k}-x_{i}^{k}\right) \\
x_{i}^{k+1}= & x_{i}^{k}+v_{i}^{k+1}
\end{aligned}
$$

Where:

$v_{i}^{k}$ is the $i$-th particle velocity in the k-iteration

$x_{i}^{k}$ is the $i$-th particle position in the k-iteration $c 1$ and $c 2$ are learning factors

$r l$ and $r 2$ are two random variables between 0 and 1 $w$ is an inertia weight

\section{Design and results}

The design using CST software with data that has been obtained from the results of the calculation is then applied to obtain an E-shaped microstrip antenna that is close to the initial design specifications. As shown in Fig. 3, this antenna rationing system uses a single probe feed that connects the patch conductor through a hole in the groundplane and shorting pin that connects the conductor patch to the groundplane.

The E-shaped patch antenna with ground follows the subtraction size. The type of substrate used in this study is FR4 Epoxy with a relative dielectric constant value $(\mathrm{r})=4.6$ and thickness $(\mathrm{h})=1.6 \mathrm{~mm}$. Feeding technique used in the connector is a probe feed technique to get matching impedance that matches the impedance of the connector which is $50 \mathrm{ohms}$.

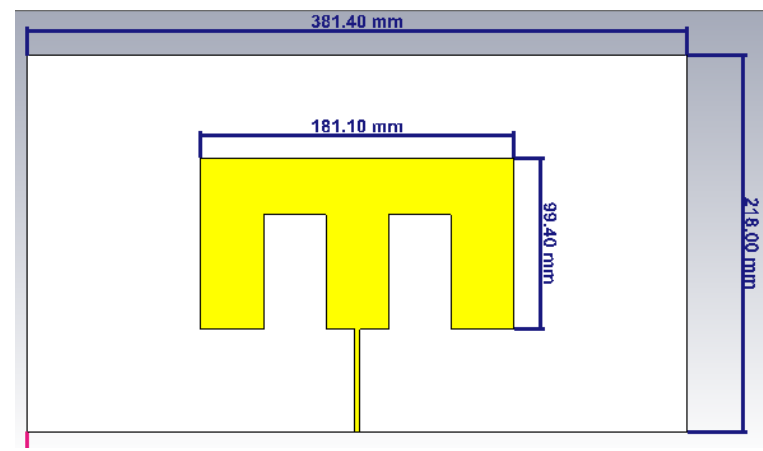

Figure. 3 The dimensions of the front antenna

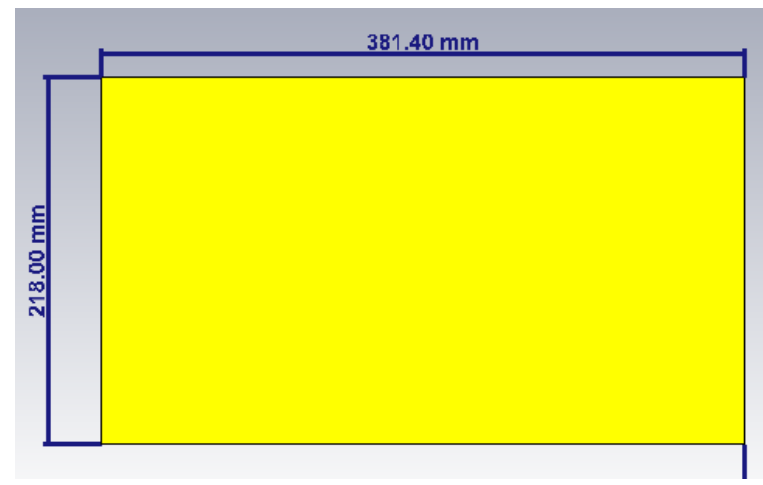

Figure. 4 The dimensions of the rear antenna

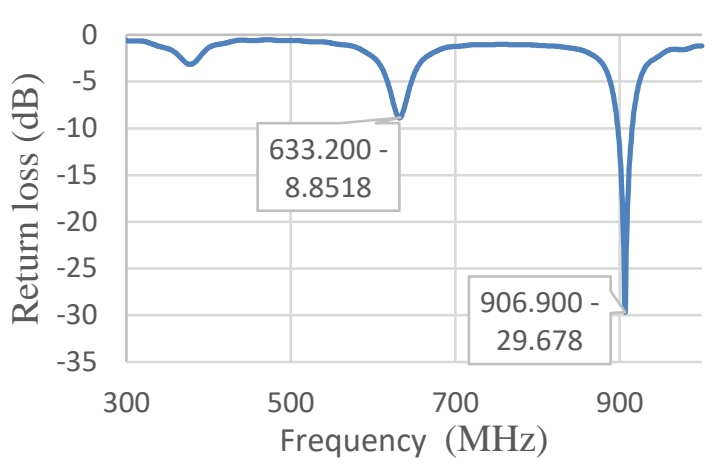

Figure. 5 The results of returnloss with the design according to calculations

Fig. 5 shows the simulation results based on the calculation results in Table 2 to see the return loss characteristics, VSWR, impedance matching and gain. These characteristics are good standards of an antenna in absorbing or receiving signals.

From the simulation results, it can be concluded that the return loss is less than optimal. The desired frequency range has not been obtained yet, the best point is at $906.9 \mathrm{MHz}$ with a return value of $-29.6 \mathrm{~dB}$ and a $633.2 \mathrm{MHz}$ frequency with a return value of $8.85 \mathrm{~dB}$. As for the impedance, it matches with 48.61 ohms, this impedance matching role is to see the reflection coefficient quality of an antenna.

\subsection{Optimization using the usual method (trial and error)}

To get the simulation results that fit the criteria, modification of the antenna dimensions is needed. Modifications to be made can include changing the dimensions of the patch, ground, and feed. To do this optimization, the first step is to choose the method used in the optimization and then determine the range for each parameter that is optimized. Furthermore, the determining of the desired goal in this simulation is dependent on the return loss value.

\subsubsection{Optimization of $L p, W p$ and $L f$ parameters}

In this optimization step, the patch portion of the antenna is optimized, which will be adjusted to the desired working frequency range. The purpose of this patch optimization is to bring out the lowest point of antenna performance, so that the range of working frequencies can be determined. Changes made are in the parameters $\mathrm{Lp}, \mathrm{Wp}$, and $\mathrm{Lf}$ as in the table.

The Lf parameter was also changed to adjust the dimensions of the E-shaped microstrip antenna so that the feed channel is still transmitted. The results obtained from this optimization process is, it has raised a low frequency point where the performance has been in the desired work frequency. However, the 
desired return loss parameter has not been reached i.e. below $-10 \mathrm{~dB}$.

\subsubsection{Optimization of Ls, Ws, and Lf}

The next stage of optimization aims to change the shape of the dimensions of the antenna into a rectangle with the distance of the patch and connector to be distant, so that the feed transmission channel becomes longer. At this stage, the optimization is done on the substract part. This dimension change aims to optimize the next optimization stage, namely in the ground optimization stage. At this stage, the partial ground technique is used, by changing the dimensions of the automatic subtraction, the dimension of the ground also changes, so that the opportunity to reduce the ground part in the optimization process will be more optimal. Changes made are in the parameters Ls, Ws, and Lf as in the Table 4.

Table 3. Optimization of dimensional changes to patches

\begin{tabular}{|c|c|c|}
\hline Parameter & $\begin{array}{c}\text { Before } \\
\text { Optimization } \\
(\mathrm{mm})\end{array}$ & $\begin{array}{c}\text { After } \\
\text { Optimization } \\
(\mathrm{mm})\end{array}$ \\
\hline$L p$ & 99.4 & 75 \\
\hline$W p$ & 181.1 & 90 \\
\hline$L f$ & 50 & 80 \\
\hline
\end{tabular}

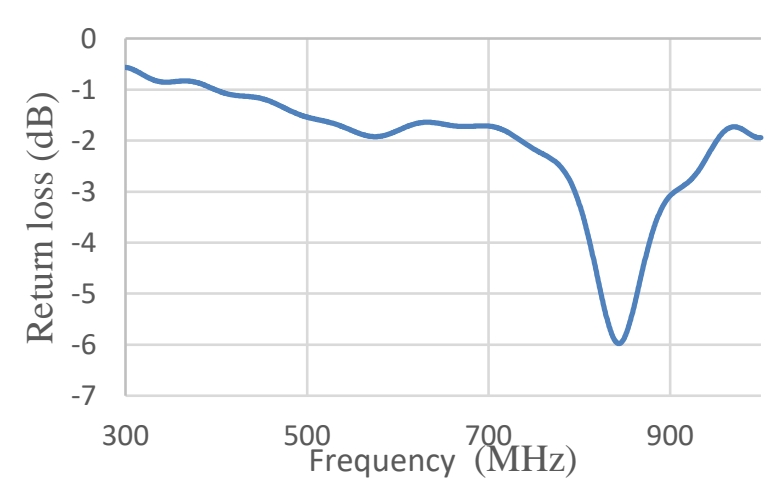

Figure. 6 Return loss result after optimization on patch

Table 4. Optimization in the subtraction section

\begin{tabular}{|c|c|c|}
\hline Parameter & $\begin{array}{c}\text { Before } \\
\text { Optimization } \\
(\mathrm{mm})\end{array}$ & $\begin{array}{c}\text { After } \\
\text { Optimization } \\
(\mathrm{mm})\end{array}$ \\
\hline$L s$ & 218 & 373.9 \\
\hline$W s$ & 381.4 & 127.8 \\
\hline$L f$ & 80 & 220 \\
\hline
\end{tabular}

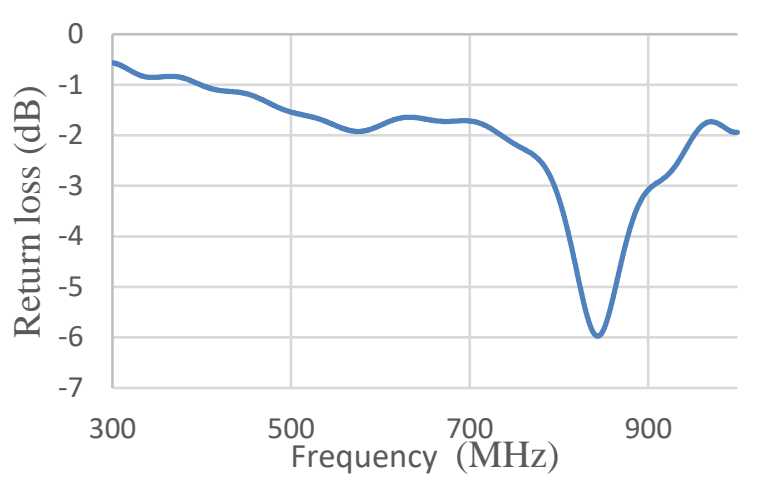

Figure. 7 Return loss results after optimization of the subtraction section

Table 5. Optimization of changes in the dimensions of the letter gap E

\begin{tabular}{|c|c|c|}
\hline Parameter & $\begin{array}{c}\text { Before } \\
\text { Optimization } \\
(\mathrm{mm})\end{array}$ & $\begin{array}{c}\text { After } \\
\text { Optimization } \\
(\mathrm{mm})\end{array}$ \\
\hline$L t$ & 60 & 36 \\
\hline
\end{tabular}

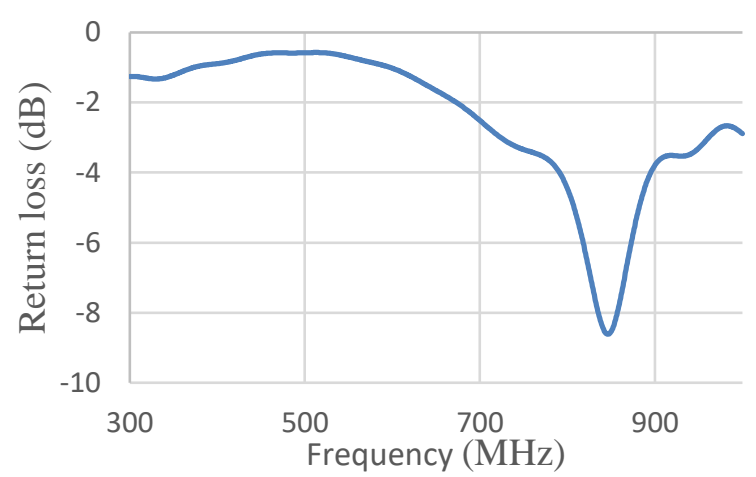

Figure. 8 Return loss results after optimization of the slit section $\mathrm{E}$

Changes in the value of Ls also follow the position of the patch so that the resulting Lf parameter is longer than before. From the substract optimization process, the results are not much different from before. That is because the optimization on the substract does not affect the quality of the received power from the antenna in receiving the information sent.

\subsubsection{Optimization of $L t$}

This optimization is one of the optimizations at the patch stage where the dominant shape of the $E$ riot is changed by reducing the gap of the E shape to shrink the gap from before. The goal is to make the electromagnetic moving around the feeder to be more stable, so that the antenna performance will get better as indicated by a decrease in return loss value. 
Table 6. Optimization of changes in ground dimensions

\begin{tabular}{|c|c|c|}
\hline Parameter & $\begin{array}{c}\text { Before } \\
\text { Optimization } \\
(\mathrm{mm})\end{array}$ & $\begin{array}{c}\text { After } \\
\text { Optimization } \\
(\mathrm{mm})\end{array}$ \\
\hline$L g$ & 373.9 & 216.8 \\
\hline
\end{tabular}
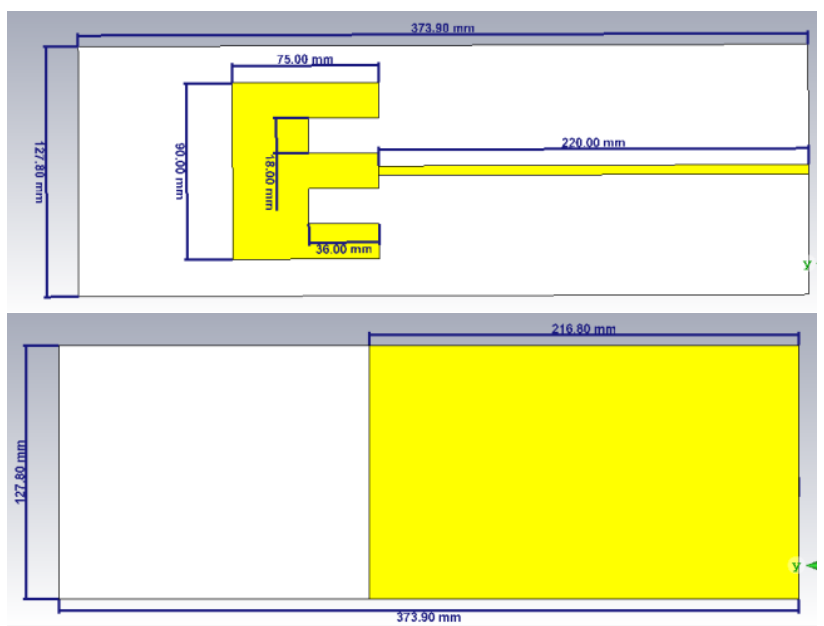

Figure. 9 Final dimension after optimization

Based on the results obtained, it can be seen that the return loss rate has decreased and the resulting valley of bandwidth is getting bigger. We can analyze that in these conditions for the next optimization step it will be very helpful so that the antenna can work according to the desired frequency.

\subsubsection{Optimization of $\mathrm{Lg}$}

This optimization step is the optimization stage of the ground portion of the antenna. This optimization is done using the partial ground method, namely by reducing the partial ground, so that the ground does not fully follow the subtraction dimension. The goal of this optimization is to reduce the return loss to the desired working frequency.

\subsubsection{The final result of optimization}

The final optimization design using the usual method obtained quite appropriate dimensions. It is because the desired working frequency is in the frequency range $400 \mathrm{MHz}-900 \mathrm{MHz}$, based on antenna law where the smaller the frequency, the resulting antenna design dimensions will be even greater.

The final dimensions of the antenna are obtained to get the working frequency of the wideband, with the antenna length of $373.9 \mathrm{~mm}$ and width $127.8 \mathrm{~mm}$.

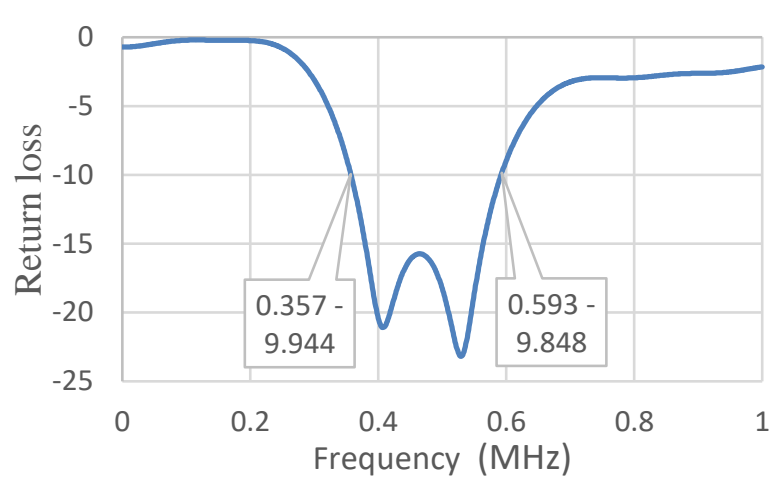

Figure. 10 The final return loss after optimization

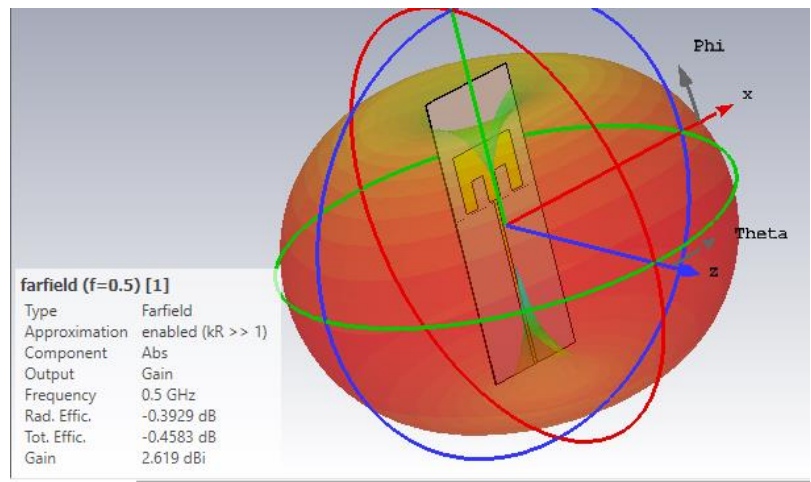

Figure. 11 Characteristics of radiation patterns and antenna gain

So, we get the best return loss value below $-10 \mathrm{~dB}$, which is on the frequency of $360-590 \mathrm{MHz}$. At that frequency, the antenna will be able to receive information that is sent perfectly. From these frequencies, a bandwidth of $230 \mathrm{MHz}$ is obtained for wideband frequencies.

The radiation pattern of the characteristics of the designed E-shaped microstrip antenna is omnidirectional. The antenna beam direction is directed towards the donut-shaped direction with the antenna as the center. This is a good characteristic when implementing antennas with a wide range or not directed in one direction only. Another characteristic of the E-shaped microstrip antenna is a gain of $2.619 \mathrm{dBi}$.

\subsection{Optimization using the PSO method}

\subsubsection{Lp optimization uses the PSO method}

When the optimization using the PSO method is done with the configuration of the optimizer settings, the first parameter that is optimized is the Lp parameter. The initial $\mathrm{Lp}$ value is $75 \mathrm{~mm}$, then using the PSO method configured to find the best value from the range of $70 \mathrm{~mm}$ to $90 \mathrm{~mm}$ in the $\mathrm{Lp}$ parameter according to Fig. 12. 


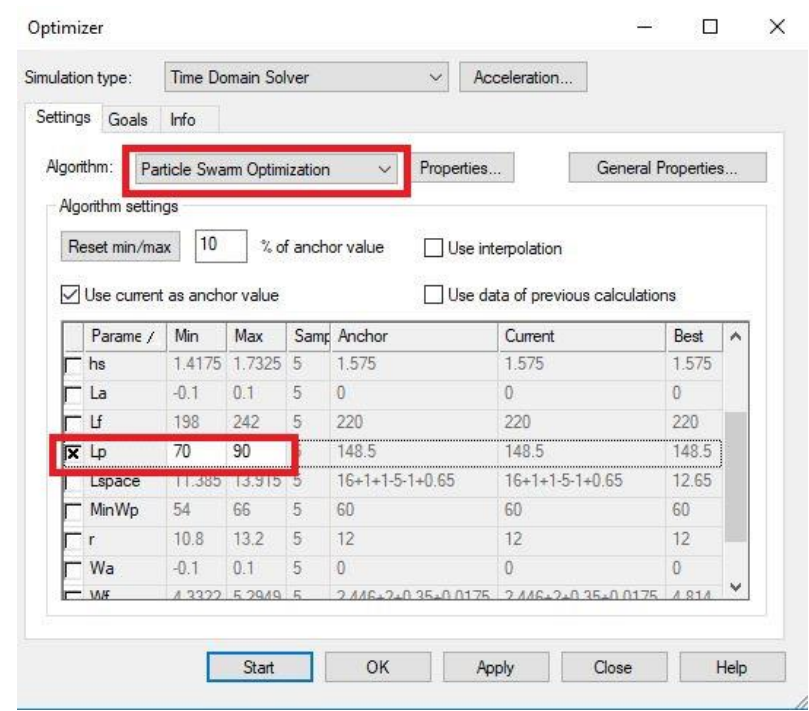

Figure. 12 Configuring the Lp parameter uses the PSO algorithm

\begin{tabular}{|c|c|c|c|c|}
\hline \multicolumn{4}{|c|}{ 1DC: IS Parameters 151,1} & Cancel \\
\hline \multicolumn{4}{|l|}{$\begin{array}{l}\text { Type } \\
\text { (C) Mag. (nea) }\end{array}$} & Result Terrobite... \\
\hline Orealpart & \multicolumn{3}{|c|}{ O Imeginary part } & Heb \\
\hline \multicolumn{4}{|l|}{ Condtions } & \\
\hline Operator: & Target: & \multirow{2}{*}{\multicolumn{2}{|c|}{$\begin{array}{l}\text { Weight: } \\
2.0\end{array}$}} & \\
\hline$\checkmark$ & -20 & & & \\
\hline पuse slope & 0.0 & \multicolumn{3}{|c|}{$\begin{array}{l}\text { Return loss target } \\
<-20 \mathrm{~dB}\end{array}$} \\
\hline \multicolumn{5}{|l|}{ Range } \\
\hline \multicolumn{2}{|l|}{ Orotal } & \multicolumn{3}{|c|}{$\begin{array}{l}\text { Frequency target } \\
400-650 \mathrm{MHz}\end{array}$} \\
\hline (-) Range min: & 0.4 & $\max :$ & 0.65 & \\
\hline \multicolumn{4}{|l|}{ Gos Norm: } & \\
\hline \multicolumn{4}{|l|}{ Maximum Difference } & \\
\hline
\end{tabular}

Figure. 13 The desired target in Lp parameter optimization using PSO algorithm

Configuring goals is the desired target of the user in designing the antenna. This target can be configured like return loss, VSWR, impedance matching and so on. The calculation is done by the software to get the pre-set tags based on the PSO method.

The optimization carried out is by configuring the target return parameter below $-20 \mathrm{~dB}$ at a frequency of $400-650 \mathrm{MHz}$ as shown in Fig. 13. It is intended that the return loss value is lower than the frequency that has been set. Where the lower the return loss value, the resulting power losses will be smaller so that the antenna can absorb information perfectly.

From the results of optimization using the PSO method on the Lp parameter, the best value for LP is

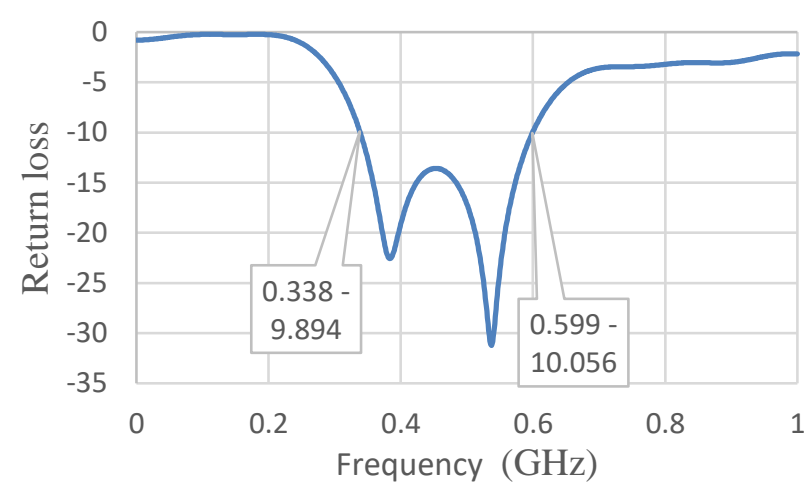

Figure. 14 Return loss results after Lp optimization using the PSO method

$88.5 \mathrm{~mm}$. It can be seen that the return loss results are decreasing at the lowest point up to $-30.3 \mathrm{~dB}$ at the frequency of $535 \mathrm{MHz}$. The return loss range $-10 \mathrm{~dB}$ is widening, which means that the bandwidth is greater. When the return loss value is below $-10 \mathrm{~dB}$, namely at a frequency of 338-600 MHz, the resulting bandwidth is $262 \mathrm{MHz}$ and greater before the use of the PSO method. As shown in Fig. 14.

\subsubsection{Wp optimization uses the PSO method}

The Wp parameter is the width of the patch antenna. The purpose of optimizing the $\mathrm{Wp}$ parameter is to widen the bandwidth so that the resulting antenna becomes a better wideband. The initial value of $\mathrm{Wp}$ is $90 \mathrm{~mm}$, then using the PSO method configured to find the best value of the range 80-100 $\mathrm{mm}$ in the Wp parameter according to Fig. 15.

The goals to be achieved are the same as the settings for Lp optimization, only that the target frequency is widened to $400-700 \mathrm{MHz}$. The software will calculate to get the target that has been previously set based on the PSO method, according to Fig. 16. From the optimization results obtained by the PSO method, the best value for the Wp parameter is $81 \mathrm{~mm}$.

After using the particle swarm optimization algorithm on the $\mathrm{Lp}$ parameter, the return value is slightly increased, but the resulting bandwidth is wider with a range below $-10 \mathrm{db}$, namely 340-635 $\mathrm{MHz}$. This is better than trial and error optimization. The range of E-shaped microstrip antenna can work in a wide frequency range or can be called wideband, with a bandwidth of $295 \mathrm{MHz}$. Table 6 shows comparison of antenna dimensions calculation, initial optimization and PSO algorithm. 
Table 6. Comparison of antenna dimensions calculation, initial optimization and PSO algorithm

\begin{tabular}{|c|c|c|c|}
\hline \multirow{2}{*}{ Parameter } & \multicolumn{3}{|c|}{ Dimention $(\mathrm{mm})$} \\
\cline { 2 - 4 } & Calculation & Initial optimization & PSO \\
\hline$L p$ & 99.4 & 75 & 88.5 \\
\hline$W p$ & 181.1 & 90 & 81 \\
\hline$L f$ & 50 & 220 & 220 \\
\hline$W f$ & 3 & 4.813 & 2.865 \\
\hline$L t$ & 120 & 36 & 36 \\
\hline$W t$ & 42 & 18 & 18 \\
\hline$W c$ & 42 & 18 & 18 \\
\hline$L s$ & 218 & 373.9 & 373.9 \\
\hline$W s$ & 381.4 & 127.8 & 127.8 \\
\hline$L g$ & 218 & 216.8 & 216.8 \\
\hline$W g$ & 381.4 & 127.8 & 127.8 \\
\hline
\end{tabular}

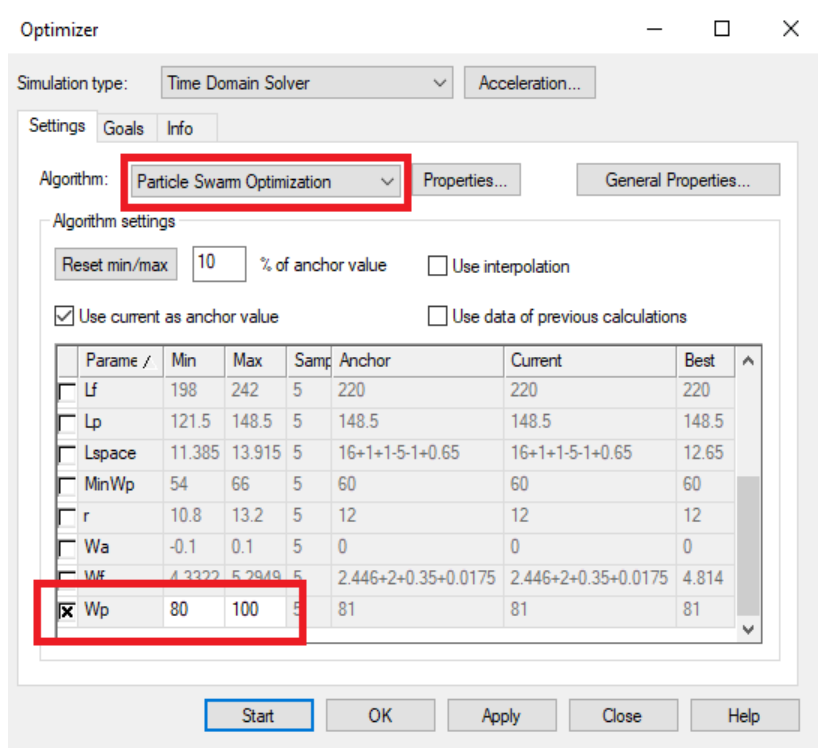

Figure. $15 \mathrm{Wp}$ optimization using PSO

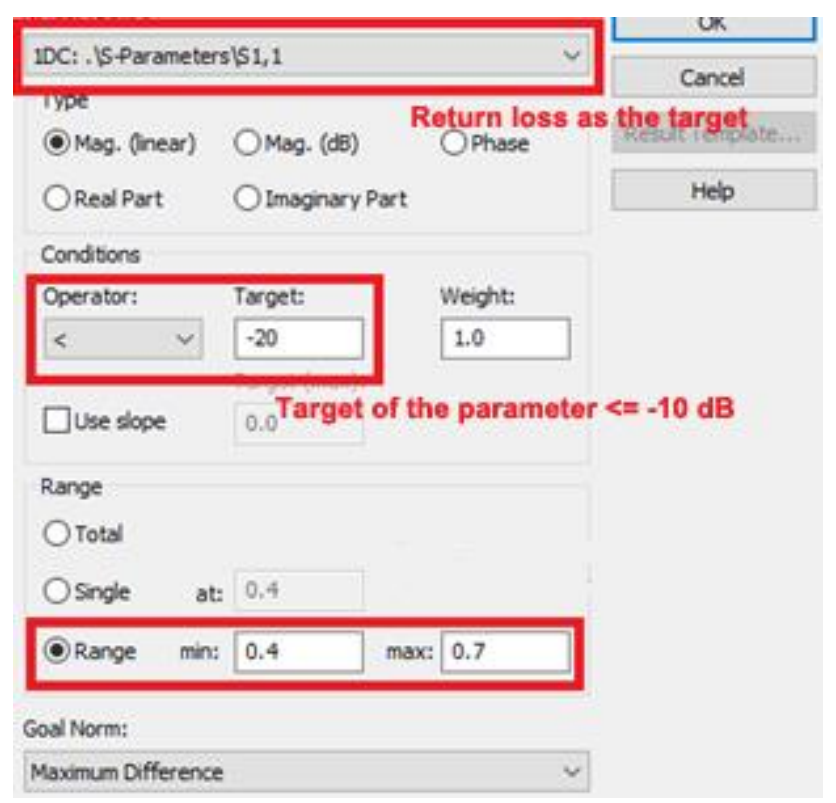

Figure. 16 The return loss target for Wp optimization using the PSO method

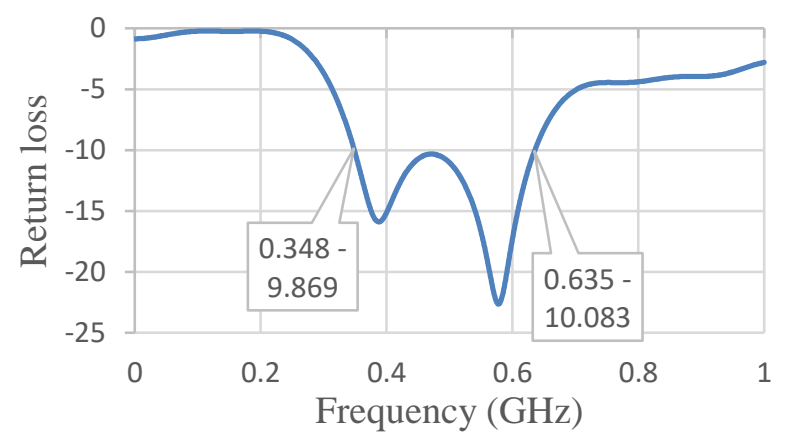

Figure. $17 \mathrm{Wp}$ optimization results using the PSO method

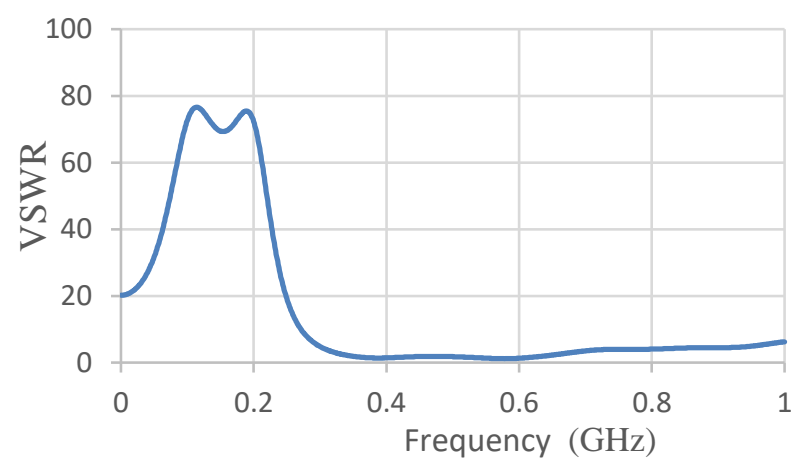

Figure. 18 The final result in VSWR antenna

\subsection{VSWR}

VSWR stands for Voltage Standing Wave Ratio, where the VSWR value will see the quality characteristics of an antenna that can receive and absorb the transmitted signal. The best graph of VSWR is in the frequency of $346-639 \mathrm{MHz}$ in the simulation, and has fulfilled the requirements of VSWR at $1 \leq \mathrm{x} \leq 2$. It proves that the antenna can work well, where the power emitted will be absorbed completely by the septum because the VSWR value is close to 1 . It can be analyzed that when the VSWR value is close to 1 , the reflection coefficient will be 0 , meaning that the transmitted signal will be absorbed completely without being reflected. 


\subsection{The radiation pattern and gain}

The radiation pattern test functions are to see the direction of wave propagation from the antenna characteristics. Due to the return loss test and VSWR that has a wideband working frequency, the radiation pattern test is also done at some of the best frequency points. Radiation depiction related to the strength of radio waves emitted by the antenna or the level of signal reception is received by the antenna at different angles. From some of the characteristics of the radiation pattern, it can be seen that the radiation pattern characteristics of the designed antenna are omnidirectional.

The working frequency of the E-shape microstrip antenna after the use of the PSO algorithm is 340-635 $\mathrm{MHz}$ with a bandwidth of $295 \mathrm{MHz}$. The antenna radiation pattern obtained is omnidirectional, where the donut-shaped radiation pattern with the direction of the wave is in all directions.

Omnidirectional antenna is a type of antenna that has a signal emitting pattern in all directions with the same power. To produce a wide coverage area, the gain of the omnidirectional antenna must focus its power horizontally (horizontally, ignoring the transmitting pattern up and down, so that the antenna can be placed in the middle of the base station). Thus, the advantage of this type of antenna is that it can serve more users.

Based on these results, it can be seen that the gain generated from the E-shaped microstrip antenna is $3.246 \mathrm{dBi}$. It is an ideal type of antenna with omnidirectional radiation pattern. That is because the reinforcement of the information sent will be stable as shown in Fig. 19.

When viewed with the antenna position parallel to the eye, the shape of the radiation pattern will resemble a bulb. That is because the characteristic radiation pattern of the E-shaped antenna is omni directional, with the best points at an angle of 30 and

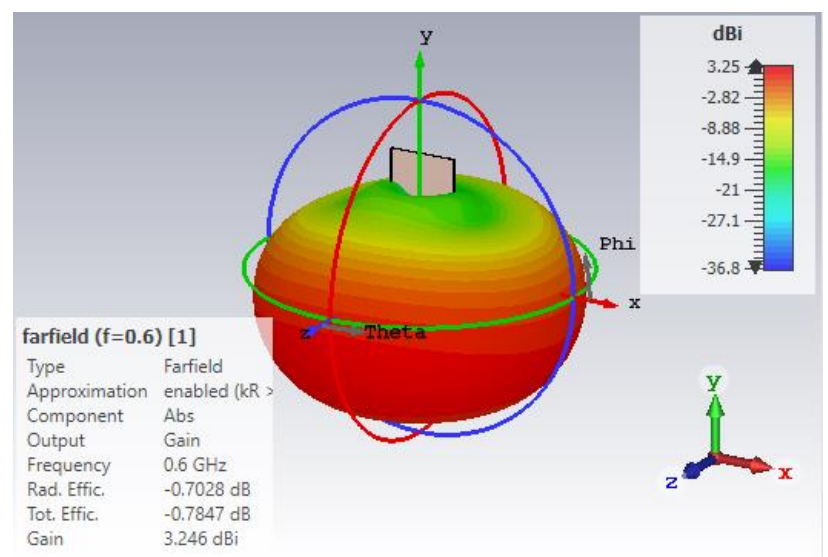

Figure. 19 Radiation pattern and antenna gain
Farfield Gain Abs (Phi=90)

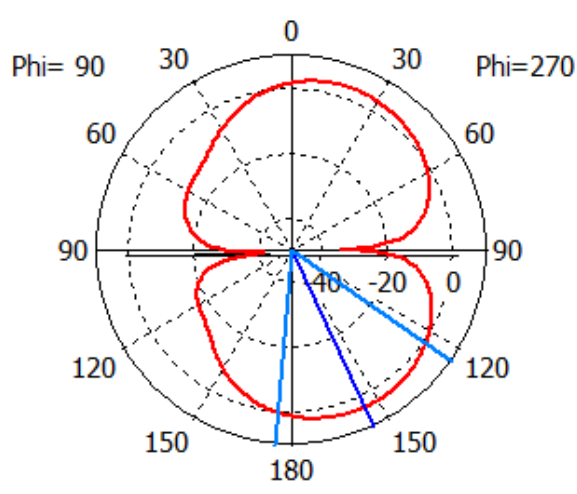

Theta / Degree vs. dBi

Figure. 20 Radiation conditions are rotated horizontally

$$
\text { Farfield Gain Abs (Theta }=90 \text { ) }
$$

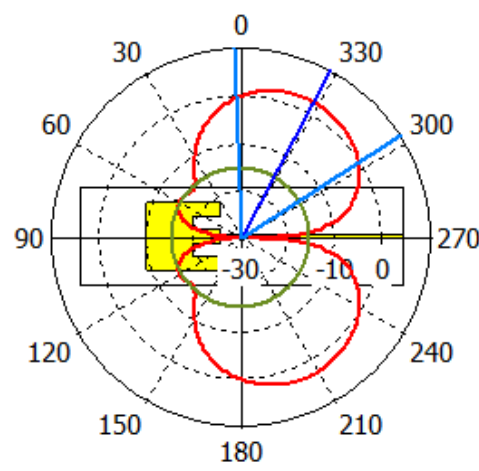

Phi / Degree vs. dBi

Figure. 21 Radiation conditions pattern rotated vertically

90 degrees. Where at that angle, the quality of the antenna receives information better than other angles. Although on average, the quality of the radiation pattern is almost similar in every angle, as shown in the picture.

Meanwhile, when the antenna position is in front of the eye, the direction of the radiation pattern is divided into two. Actually, it is a connected radiation pattern pathway that is likened to a donut. That is because the characteristic radiation pattern of the Eshaped antenna is omnidirectional, with the best points being at angles of 210 and 330 degrees.

\section{Conclusion}

Based on the data obtained from the simulation results it can be concluded as follows:

1. Return loss and VSWR results of antenna simulation show that the E-shaped microstrip antenna can work well in several wideband frequencies with return loss values below -10 
$\mathrm{dB}$ and VSWR at $1<\mathrm{X}<2$ for frequency 340 $635 \mathrm{MHz}$.

2. Antenna radiation pattern results from the simulation are omnidirectional, with the best results at an angle of $210^{\circ}$ and $330^{\circ}$ when in the vertical conditions, while the horizontal conditions are the best conditions at an angle of $30^{\circ}$ and $90^{\circ}$.

3. The gain generated by the antenna is 3.246 $\mathrm{dBi}$, which is ideal for an antenna type with an E-Shaped microstrip antenna that has omnidirectional radiation pattern.

4. The use of the Particle Swarm Optimization method is very instrumental in the application of wideband type antennas.

In our next research we will use the Genetic Algorithm for the optimization of E-shaped microstrip antennas. Then the results of this optimization will be compared with the existing PSObased optimization.

\section{Conflicts of Interest}

The authors declare that there is no conflict of interest in the paper. There are no personal circumstances of interest that may be perceived as inappropriately influencing the representation or interpretation of reported research results.

\section{Author Contributions}

Yulindon Yulindon responsible on writingoriginal draft preparation and software, provided the resources, set the paper visualization, keep the funding acquisition, did the data curation, project administration and participated in methodology. Noor Azah Samsudin responsible for investigation, supervision and participated in methodology and validation. Riswan Efendi carried out the formal analysis, writing - review and editing and participated in validation. All authors work on conceptualization of the paper.

\section{References}

[1] N. Jin and Y. Rahmat-Samii, "Particle Swarm Optimization for Antenna Designs in Engineering Electromagnetics", J. Artif. Evol. Appl., vol. 2008, pp. 1-10, 2008.

[2] R. Golubovic and D. Olcan, "Antenna optimization using Particle Swarm Optimization algorithm", J. Autom. Control, Vol. 16, No. 1, pp. 21-24, 2006.

[3] Y. Rahmat-Samii and N. Jin, "Particle swarm optimization (PSO) in engineering electromagnetics: A nature-inspired evolutionary algorithm", In: Proc. of 2007 Int. Conf. Electromagn. Adv. Appl. ICEAA'07, pp. 177-182, 2007.

[4] Z. D. Zaharis, I. P. Gravas, T. V. Yioultsis, P. I. Lazaridis, I. A. Glover, C. Skeberis, and T. D. Xenos, "Exponential Log-Periodic Antenna Design Using Improved Particle Swarm Optimization with Velocity Mutation", IEEE Trans. Magn., Vol. 53, No. 6, pp. 2015-2018, 2017.

[5] S. Sahoo, L. P. Mishra, and M. N. Mohanty, "Optimization of Z-Shape Microstrip Antenna with I- slot Using Discrete Particle Swarm Optimization (DPSO) Algorithm", Procedia Comput. Sci., Vol. 92, pp. 91-98, 2016.

[6] A. Elhamraoui, E. Abdelmounim, J. Zbitou, H. Bennis, and M. Latrach, "A New Design of a Microstrip Antenna with Modified Ground for RFID Applications", International Journal of Intelligent Engineering and Systems, Vol. 11, No. 6, pp. 44-51, 2018.

[7] S. K. Goudos, A. Tsiflikiotis, D. Babas, K. Siakavara, C. Kalialakis, and G. K. Karagiannidis, "Evolutionary design of a dual band E-shaped patch antenna for 5G mobile communications," In: Proc. of 2017 6th International Conference on Modern Circuits and Systems Technologies (MOCAST), pp. 1-4, 2017.

[8] S. Nagaraju, B. V Kadam, L. J. Gudino, S. M. Nagaraja, and N. Dave, "Performance analysis of rectangular, triangular and E-shaped microstrip patch antenna arrays for wireless sensor networks", In: Proc. of 2014 International Conference on Computer and Communication Technology (ICCCT), pp. 211215, 2014.

[9] S. Liu, W. Wu, and D.-G. Fang, "Single-Feed Dual-Layer Dual-Band E-Shaped and U-Slot Patch Antenna for Wireless Communication Application”, IEEE Antennas Wirel. Propag. Lett., Vol. 15, pp. 468-471, 2016.

[10] W. Ao, W.-Q. Xiang, C.-M. Chen, W. Tian, and D.-B. Zhang, "Analysis and Design of E-Shaped Dual-frequency Microstrip Antenna Based on CPSO Algorithm", In: Proc. of the 2nd International Conference on Computer Science and Electronics Engineering (ICCSEE 2013), 2013.

[11] I. B. Pauria, S. Kumar, and S. Sharma, "Design and Simulation of E-Shape Microstrip Patch Antenna for Wideband Applications", Int. J. Soft Comput. Eng., Vol. 2, No. 3, pp. 275-280, 2012. 
[12] A. A. Roy, J. M. Môm, and G. A. Igwue, "Enhancing the Bandwidth of a Microstrip Patch Antenna using Slots Shaped Patch", American Journal of Engineering Research, Vol. 2, No. 9, pp. 23-30, 2013.

[13] N. Misran and M. Islam, "Design and Development of Broadband Inverted E-shaped Patch Microstrip Array Antenna For 3G Wireless Network", Am. J. Appl. Sci., Vol. 5, No. 4, pp. 427-434, 2008.

[14] B. Santosa and P. Willy, Metaheuristics Method - Concept and Implementation, I. Surabaya: Guna Widya Publisher, 2011. 